\title{
Nascimentos da cegonha: experiência de puérperas assistidas pela enfermagem obstétrica em Centro de Parto Normal
}

Stork Network births: The experience of puerperal women assisted by Obstetric Nursing in a Normal Delivery Center

Nascimentos da cegonha: experiência de puérperas assistidas pela enfermagem obstétrica em Centro de Parto Normal

\section{Bruna Cristina de Araujo Lima ${ }^{\mathrm{I}}$, Hevelyn Kelly Samara Leite de Almeida ${ }^{\mathrm{II}}$, Mônica Cecília Pimentel de Melo ${ }^{I I I}$, Ramon José Leal de Morais ${ }^{\mathrm{IV}}$}

\begin{abstract}
Resumo: Objetivo: analisar as percepções e sentimentos de puérperas acerca das experiências do parto assistido pela enfermagem obstétrica em Centro de Parto Normal (CPN), no contexto da Rede Cegonha. Método: pesquisa qualitativa, exploratória e descritiva, realizada com 14 puérperas assistidas em CPN do sertão nordestino, as entrevistas ocorreram de abril a maio de 2018 e o material foi discutido segundo análise temática de conteúdo. Resultados: os relatos apontaram uma assistência acolhedora, com formação de vínculo e boas práticas de assistência ao parto. Uma desinformação em relação ao papel da enfermagem no nascimento revelou-se no conteúdo. As puérperas descrevem a estrutura física disponível no CPN como ambiente de tranquilidade, conforto e privacidade. Conclusão: a assistência prestada pela enfermagem obstétrica em CPNs influencia positivamente nas experiências de parturientes. Nesse contexto, uma assistência humanizada em local apropriado é indispensável para que o processo de parir transcorra sem complicações proporcionando segurança, satisfação e bem estar.

Descritores: Enfermagem obstétrica; Parto normal; Assistência ao parto; Humanização da assistência; Saúde da mulher
\end{abstract}

Abstract: Objective: to know the perception of the multi-professional team regarding the strategies for the safety
of pediatric patients in critical areas. Method: a qualitative and exploratory-descriptive study carried out in
pediatric intensive care and emergency units of three hospitals in the city of Porto Alegre, between November 2018
and March 2019, linked to the matrix project entitled "Patient safety in hospital care services for children and

${ }^{\text {I }}$ Acadêmica de Enfermagem, Graduanda de enfermagem, Universidade Federal do Vale do São Francisco, Petrolina, Pernambuco, Brasil. Email: brunacristinalima95@gmail.com; Orcid: https://orcid.org/0000-0002-5863-620X

${ }^{I I}$ Acadêmica de Enfermagem, Graduanda de enfermagem, Universidade Federal do Vale do São Francisco, Petrolina, Pernambuco, Brasil. Email: hevelynkelly@hotmail.com; Orcid: https://orcid.org/0000-0002-1722-3994

III Enfermeira, Doutora, Universidade Federal do Vale do São Francisco, Petrolina, Pernambuco, Brasil. E-mail: monquinamelo@gmail.com; Orcid: https://orcid.org/0000-0003-4029-4886

IV Enfermeiro, Mestre, Universidade Federal do Vale do São Francisco, Petrolina, Pernambuco, Brasil. E-mail: Ramonmorais_dm@hotmail.com; Orcid: https://orcid.org/0000-0002-2099-6074 
Nascimentos da cegonha: experiência de puérperas assistidas pela enfermagem obs... | 2

adolescents in the city of Porto Alegre". A total of 20 practitioners who worked in these areas and who had experience in pediatrics for at least one year were included. Five collective interviews were conducted, which were audio-recorded and later transcribed for content analysis. Results: three categories arose: Maintenance of adherence to the protocols/goals of pediatric patient safety, Teaching/education in patient safety, and Involvement of companions for the promotion of patient safety. Conclusion: the practitioners acknowledge that the strategies described demonstrate minimal conditions to reach care quality and incident prevention, essential for patient safety.

Descriptors: Patient safety; Child, hospitalized; Health personnel; Health services; Organizational culture

Resumen: Objetivo: conocer la percepción del equipo multidisciplinario sobre las estrategias de seguridad del paciente pediátrico en áreas críticas. Método: estudio cualitativo descriptivo y exploratorio realizado en unidades de cuidados intensivos y urgencias pediátricas de tres hospitales de la ciudad de Puerto Alegre, entre noviembre de 2018 y marzo de 2019, vinculado al proyecto matricial "Seguridad del paciente en servicios de atención hospitalaria para niños y adolescentes de la ciudad de Puerto Alegre”. Se incluyó a 20 profesionales que trabajaban en estas áreas y tenían al menos un año de experiencia en pediatría. Se realizaron cinco entrevistas colectivas, grabadas en audio y luego transcriptas para análisis de contenido. Resultados: surgieron tres categorías: Mantenimiento de la adherencia a los protocolos/metas de seguridad del paciente pediátrico, Enseñanza/ educación en seguridad del paciente e Implicación de los acompañantes para promover la seguridad del paciente. Conclusión: los profesionales perciben que las estrategias descriptas demuestran condiciones mínimas para alcanzar la calidad de la atención y prevención de incidentes, imprescindibles para la seguridad del paciente.

Descriptores: Seguridad del paciente; Niño hospitalizado; Personal de salud; Servicios de salud; Cultura organizacional

\section{Introdução}

O parto e a consequente chegada de um filho podem ser eventos memoráveis na vida de uma mulher. Esse momento, antes íntimo e domiciliar, passou por diversas transformações ao longo dos anos, com destaque para a alteração do ambiente de nascimento, do domicílio para o hospital. ${ }^{1}$ Após tal mudança, a mulher passou a ser submetida a procedimentos assistidos por profissionais de saúde, resultando em um declínio da sua autonomia no processo de parir. ${ }^{2}$

Inserida em um novo contexto, a sociedade começou a criar uma imagem estereotipada do processo parturitivo, associando-o, quase sempre, à dor e ao sofrimento. Desde então, a percepção natural do parto transformou-se em um acontecimento patológico, potencializando a introdução de intervenções que buscam o alívio da dor e do sofrimento e, de certo modo, 
contribuem para a consolidação de um modelo biomédico e hospitalocêntrico na assistência à parturiente. ${ }^{3}$

Compreendendo a conjuntura apresentada, a Organização Mundial da Saúde (OMS), visando à humanização do parto e a mudança do modelo de atenção obstétrica vigente, passa a discutir alguns desses procedimentos quanto suas recomendações, respaldo científico e segurança da saúde materna. Posto isto, as agências reguladoras e especializadas em saúde vêm tentando estabelecer boas práticas para a atenção ao parto e nascimento. Contudo, o Brasil, em comparação aos principais países desenvolvidos, apresenta indicadores preocupantes de morbimortalidade materna e infantil e acredita-se que, o modelo de assistência adotado contribua para esses dados. ${ }^{4}$

O Ministério da Saúde do Brasil, a partir da estratégia Rede Cegonha, endossa as recomendações científicas propostas pela OMS, incluindo entre elas, a implantação de Centros de Partos Normais (CPNs), ambientes que têm como objetivo oferecer maior conforto, comodidade e privacidade às parturientes durante o Pré Parto, Parto e Puerpério. Essas estruturas vão ao encontro a um novo modelo de atenção obstétrica, na tentativa de devolver à mulher a sua autonomia no momento do parto. ${ }^{5}$

Os CPNs trazem em sua essência a percepção natural do parto, respeitando a relação do binômio mãe-filho e resgatando a figura da família por meio da presença do acompanhante na assistência ao nascimento. Tratam-se de novos serviços que podem ser constituídos em instalações hospitalares ou extra-hospitalares, geridos, exclusivamente, pela enfermagem obstétrica, que também é responsável por toda assistência à mulher, possibilitando uma reconquista da autonomia da parturiente e de espaço de atuação para a enfermagem obstétrica no que tange ao modelo biomédico. ${ }^{6}$

Apesar da relevância dessas instalações para assistência ao parto, existe ainda um desconhecimento por parte da população a despeito dos propósitos e da importância destas 
Nascimentos da cegonha: experiência de puérperas assistidas pela enfermagem obs... $\mid 4$

novas estruturas, bem como da assistência prestada pelos profissionais que as constituem. Diante disso, estabeleceu-se como questão de pesquisa: quais as percepções e sentimentos de puérperas envolvidas em uma assistência ao parto prestada pela enfermagem obstétrica em CPN? Logo, a relevância desta pesquisa se dá quando se propõe construir subsídios científicos que visem avaliar modelos de assistências da teoria à prática, possibilitando melhorias na assistência da população e proporcionando uma releitura de práticas profissionais. Ressaltando ainda a necessidade de novos estudos focados na interface do cuidado e satisfação das mulheres. ${ }^{7}$

Visto isso, na tentativa de responder a esse questionamento objetivou-se analisar as percepções e sentimentos de puérperas acerca das experiências do parto assistido pela enfermagem obstétrica em CPN, no contexto da Rede Cegonha.

\section{Método}

Trata-se de uma pesquisa de campo com abordagem qualitativa de caráter exploratório e descritivo, ${ }^{8}$ que foi realizada em um CPN intra-hospitalar do sertão nordestino. Inaugurado em 2013, o CPN em questão encontra-se nas instalações de uma Maternidade Municipal e tem como objetivo prestar assistência de baixa complexidade às mulheres da Região Integrada do Desenvolvimento (RIDE) do submédio do vale do São Francisco.

Fizeram parte do estudo 14 puérperas assistidas pela enfermagem obstétrica, no período de abril a maio de 2018 , as quais foram eleitas por amostra não probabilística, atendendo aos seguintes critérios de inclusão: ter idade acima de 18 anos, estarem no puerpério mediato e em condições físicas e psicológicas para responder às perguntas realizadas. O critério de exclusão foi: puérperas que não concluíram a entrevista.

O material empírico foi obtido mediante abordagem individual das puérperas em enfermarias individualizadas do CPN, nesse mesmo espaço, foram convidadas a participar da 
5 | Lima BCA, Almeida HKSL, Melo MCP, Morais RJL

entrevista. No intuito de garantir sigilo e privacidade das entrevistadas, as puérperas foram conduzidas a local privativo, na mesma unidade ou em sua enfermaria individualizada, na ausência do seu acompanhante. Mesmo depois de dadas informações acerca do sigilo e confidencialidade, houve cinco recusas para a participação na pesquisa, ocasionadas por uma aversão das mulheres ao uso do gravador.

Realizaram-se entrevistas semiestruturadas, que foram encerradas após saturação teórica das informações. Constaram nesta etapa, levantamento de dados para caracterização sociodemográfica e obstétrica, além de questões norteadoras acerca das experiências do parto assistido por enfermeiros obstetras em CPN. As mulheres foram direcionadas às seguintes abordagens: "Conte-me como foi a experiência do seu parto?”; "Na sua visão, qual o papel do enfermeiro obstetra na assistência ao parto? Conte-me um pouco da sua experiência em ter sido assistida por um enfermeiro obstetra no momento do parto"; "Você tinha conhecimento que este profissional poderia fazer seu parto? Conte-me o que mais marcou da assistência prestada pelo enfermeiro que realizou o seu parto"; "Você acredita que o ambiente (estrutura do CPN) possa ter influenciado de forma positiva ou negativa para o seu parto, como?"; "Você ficou satisfeita com o parto que teve?”. As entrevistas foram gravadas e tiveram duração média de 30 minutos.

A análise e discussão do material basearam-se na Análise Temática de Conteúdo, ${ }^{8}$ que a descreve em três fases: pré-análise, etapa em que as entrevistas foram transcritas para que se obtivesse uma organização dos dados colhidos; fase de exploração do material, em que todo o material foi dividido em grupos semelhantes sempre em volta do contexto do estudo. Neste método, buscou-se agrupar as informações colhidas organizando-as em expressões ou palavras significativas a partir desse conteúdo colhido. Por fim, na terceira fase, do tratamento dos resultados e interpretação, os dados obtidos foram analisados e interpretados para que se tornassem significativos e válidos. ${ }^{8}$ De acordo com a realização das entrevistas, as puérperas 
Nascimentos da cegonha: experiência de puérperas assistidas pela enfermagem obs... | 6

foram identificadas com nomes de Deusas da Mitologia Grega, garantindo seu sigilo e anonimato.

A partir dessa análise, tornou-se possível o agrupamento de cinco categorias, denominadas: Recepção e acolhimento na prática obstétrica; Rede Cegonha e as boas práticas na assistência ao parto e nascimento; Da cultura do modelo obstétrico tradicional à experiência atual; Papel da enfermagem obstétrica no cenário do parto e, por fim, Influência da estrutura do CPN na assistência ao parto.

Todas as entrevistadas assinaram o Termo de Consentimento Livre e Esclarecido, e receberam uma via do mesmo. A pesquisa foi conduzida de acordo com os padrões éticos exigidos (Resolução 466/2012, do Ministério da Saúde), aprovada pelo Comitê de Ética e Pesquisas da Universidade Federal do Vale do São Francisco, sob o parecer nํo 2.548 .096 em 16 de março de 2018.

\section{Resultados}

Contribuíram para a pesquisa 14 puérperas assistidas pela enfermagem obstétrica em CPN, com idades entre 18 e 29 anos e média de 23,5. Sendo oito primíparas e as demais multíparas. Nove mulheres declararam terem naturalidade baiana. Quanto à escolaridade, predominou o ensino médio completo. Em relação à profissão, a maioria relatou ser dona de casa, no entanto também fizeram parte do estudo: comerciante, babá, pescadora e trabalhadora rural. No que se refere ao estado civil, participaram sete mulheres casadas e sete mulheres solteiras.

\section{Recepção e acolhimento na prática obstétrica}

Esta categoria aborda as principais práticas utilizadas na assistência ao parto prestada pela enfermagem obstétrica. Os depoimentos retratam uma assistência à luz do acolhimento e 
da formação de vínculo, práticas avaliadas pelas mulheres como importantes para o momento, funcionando como terapia para alívio da dor. Práticas simples foram relatadas, tais como, orientação, afeto, carinho e incentivos.

[...] Me receberam muito bem [as enfermeiras], me ajudaram, disseram algumas coisas para eu fazer para aliviar a dor [...] e vinha toda hora aqui ver como era que eu estava. (Hera)

[...] elas [as enfermeiras] me abraçaram, me desejaram boa sorte, me aconselharam [...] as meninas foram bem atenciosas. Eu me senti muito bem acolhida. (Atena)

Elas [as enfermeiras] me receberam bem [...] foi bom. (Hebe)

[...] Pessoas muito dedicadas ao trabalho que me deram muita atenção e realizaram meu parto com muito carinho. [...] me incentivou [a enfermeira], me deu muita força e me deu coragem também porque tem gente que é desumano e elas [enfermeiras] não. (Hemera)

Dessa maneira, esta categoria nos permitiu compreender que o acolhimento e a humanização andaram lado a lado, que tecnologias leves foram ferramentas essenciais para um bom acolhimento e estreitamento de vínculos.

\section{Práticas utilizadas na assistência ao parto e nascimento}

Tal categoria permitiu o agrupamento de depoimentos referentes ao desempenho de boas práticas na assistência ao parto e nascimento recomendados pela OMS e Ministério da Saúde do Brasil. Foi citado nos relatos, o estímulo à prática de exercícios para alívio da dor, orientação de técnicas de respiração, orientação e apoio emocional, realização da monitorização fetal por meio da ausculta intermitente dos batimentos cardiofetais (BCFs), incentivo à dieta, bem como a presença de acompanhante.

[...] Eu percebi que teve esse cuidado, me orientou [a enfermeira] a fazer os exercícios de bola, os exercícios no cavalinho que é esse aparelho que ajuda também. (Atena) 
Nascimentos da cegonha: experiência de puérperas assistidas pela enfermagem obs... $\mid 8$

[...] de uma em uma hora ela [a enfermeira] fica vindo escutar o coraçãozinho do bebê dentro da barriga [...] mandando tomar banho com água quente para o corpo relaxar, trazendo um mingau para ficar forte para a pessoa conseguir ter força para ter o bebê. (Aurora)

Ela [a enfermeira] me ajudou muito, se não fosse ela eu não sei o que teria sido de mim e de Julia [bebê] não. Era uma me acalmando, outra me ensinando a respirar. (Gaia)

Graças a Deus as meninas [as enfermeiras] me ajudaram muito e minha cunhada também que estava me acompanhando. (Héstia)

Apesar dos relatos apontarem para uma assistência baseada em boas práticas, raros depoimentos permitiram identificar a utilização de práticas consideradas inadequadas, no contexto da Rede Cegonha, principalmente em ambientes como os CPNs, como foi o caso do uso da ocitocina para indução do trabalho de parto.

[...] eu fiz exercício até os sete cm de dilatação, depois eu não quis fazer mais porque eu não aguentava mais. A dor era muito forte. Aí quando chegou nos nove, eles [os enfermeiros] induziram, colocaram o soro para a menina nascer. (Aurora)

Apesar das puérperas desconhecerem o que são e quais são as boas práticas de atenção ao parto e nascimento, se torna evidente ao interpretar os seus relatos, que há, majoritariamente, a adoção de práticas baseadas em evidências científicas à luz de recomendações da Rede Cegonha e da OMS por parte da Enfermagem Obstétrica do CPN em questão.

\section{Da cultura do modelo obstétrico tradicional à experiência atual}

Os depoimentos abordam as experiências vivenciadas pelas participantes, suas impressões positivas e negativas ao modelo de assistência proposto pela enfermagem obstétrica do CPN. No geral, os relatos apontam experiências marcantes e positivas da assistência prestada 
9 | Lima BCA, Almeida HKSL, Melo MCP, Morais RJL

pela Enfermagem, mesmo diante da desconfiança, gerada por experiências anteriores ou relatos de outros (blogs, colegas e vizinhos).

[...] Eu sempre via alguém falando mal, que eles [os enfermeiros] iam fazer isso, que eles iam fazer aquilo, só que não, foi tudo diferente. (Têmis)

[...] Eu fiquei surpreendida, porque veio de quem eu menos esperava e teve um bom resultado porque a gente não esperava dela [a enfermeira] e ela fez um bom parto. Assistência boa mesmo. (Electra)

Eu via muito assim nos blogs o povo reclamando daqui [a maternidade] [...] eu pensei que eu ia ficar do mesmo jeito, quando chegou aqui um quarto só para mim, tudo bem [...] eu nunca nem que esperava estar aqui. (Hemera) [...] Apesar de que eu não pari na sala de parto [...]. Do começo do meu parto, até o fim, até agora marcou tudo. Foi ótimo, para mim foi ótimo. (Tálassa)

A busca por um modelo obstétrico tradicional ainda pode ser observada nos depoimentos das mulheres assistidas, fazendo com que haja uma expectativa quanto à realização de procedimentos e intervenções atualmente desencorajados. Como toda expectativa pode estar consequentemente atrelada a uma frustração, a ausência de práticas esperadas levou ao relato de insatisfação de uma das puérperas assistida.

[...] Assim, eu só não gostei muito porque elas [as enfermeiras] ficavam mais olhando e incentivando [...] só tocaram mesmo quando a cabecinha dela já estava mais para fora e aí eu achei estranho porque lá [cidade que ela pariu o filho anterior] é diferente daqui, lá elas ajudam a botar para fora, tipo, elas pressionam a barriga, elas fazem alguma coisa e aqui não. (Afrodite)

Diante dos depoimentos das puérperas, nota-se que apesar de a maioria relatar satisfação com o modelo obstétrico baseado em evidências científicas, ainda há certa insegurança advindo do desconhecimento.

Papel da enfermagem obstétrica no cenário do parto 
Nascimentos da cegonha: experiência de puérperas assistidas pela enfermagem obs... | 10

A respeito do conhecimento acerca da participação da Enfermagem Obstétrica no cenário do parto, foi notada, nos depoimentos da maioria, uma desinformação no que tange ao papel desta categoria profissional na assistência ao parto e nascimento. Quando a informação se fez presente nos relatos esta se deu na própria maternidade ou por intermédio dos profissionais de enfermagem contidos no seu meio social.

[...] Nunca tive conhecimento de que podia o enfermeiro fazer, mas eu desconfiava que podia. (Febe)

[...] Eu não sabia, mas aí na hora ela [a enfermeira] fez. (Aurora)

[...] Eu sabia, por que lá no pré-parto ela [a enfermeira] já tinha feito outros partos antes de mim. (Íris)

[...] Eu tenho uma amiga que eu fiz amizade com ela durante minha gestação que ela é enfermeira obstetra. (Atena)

Lá embaixo [Urgência Obstétrica] elas tinham comentado que se não fosse o médico seria a enfermeira chefe [...]. Foi 100\%, é excelente ela. (Artemis)

Observa-se a necessidade de um maior engajamento da categoria de enfermagem para valorização e difusão de suas atribuições. Assim, entende-se que o pré-natal é um dos momentos mais oportunos para que as gestantes sejam orientadas sobre os profissionais aptos à assistência, uma vez que a mulher bem informada terá maior discernimento a respeito de quem a atendeu e consequentemente menos angústia e medos advindos de informações perpassadas popularmente tanto em relação aos profissionais como a respeito das instalações físicas que irão recebê-las.

\section{Influência da estrutura do CPN na assistência ao parto}

Segundo as puérperas, as experiências, em geral foram positivas, por proporcionar tranquilidade, conforto e privacidade, chegando a ser comparado, por algumas, com hospitais particulares. Esta categoria destaca ainda os equipamentos e mobília que constituem a estrutura, pois permitiu que fossem feitos exercícios recomendados pela enfermagem obstétrica. 
11 | Lima BCA, Almeida HKSL, Melo MCP, Morais RJL

Eu estava bem à vontade, eu estava sozinha num quarto, tem banheiro e tudo. [...] tinha os objetos de fazer exercícios que me ajudaram muito. (Íris) [...] eu estou me sentindo em um hospital particular na questão da instalação porque eu fiquei num quarto em que tem um armário, tem um leito só para mim, tem um banheiro, tenho privacidade. (Atena)

Eu creio que ajudou bastante, aqui é um lugar bastante adequado mesmo. Por conta que aqui tem a bola que ajuda bastante, tem o cavalinho, fora o apoio delas [as enfermeiras] que sempre estão ali em cima. (Electra)

[...] Eu fiquei sozinha no quarto, tudo em silêncio, aí a pessoa fica mais concentrada para fazer os exercícios e tudo, não tinha ninguém no quarto só eu e minha mãe que era a acompanhante. (Aurora)

Os relatos demonstram um contentamento das puérperas com relação às instalações físicas do CPN e que o modelo estrutural adotado tem se mostrado eficaz para contribuir na garantia do conforto e privacidade, gerando sentimento de bem estar e colaborando para o bom progresso do trabalho de parto.

\section{Discussão}

A assistência da enfermagem obstétrica demonstrada nos resultados pautou-se principalmente no acolhimento, o qual pode ser definido como o ato ou efeito de acolher, uma ação e uma atitude de inclusão. É considerado como um dos meios fundamentais para a humanização dos serviços de saúde, não sendo reduzido apenas a um espaço, mas sim como uma postura ética que culmina em compartilhamento de conhecimentos e temores, podendo ser feito por qualquer profissional do serviço, tomando para si a responsabilidade de "abrigar e acolher". 9

Uma recepção humana somada com uma escuta qualificada e atenta para as queixas, dores, receios e angústias, além de mantê-las orientadas, permite a compreensão do momento pelo qual as mulheres estão passando. Além disso, considerar suas condições de sujeitos 
biopsicossociais, pode culminar no estabelecimento dos vínculos entre os atores envolvidos e no respeito ao princípio de integralidade do Sistema Único de Saúde (SUS). ${ }^{10}$

A relação interpessoal estabelecida pela enfermagem obstétrica e suas ações de conforto e alívio das dores utilizadas em todas as etapas da assistência ao parto, conforme apontam os depoimentos, torna o ambiente mais aconchegante e tranquilo para a mulher, o que pode contribuir para que o parto transcorra isento de intervenções. Neste sentido, as parturientes precisam ser acolhidas e compreendidas, tratadas de maneira singular, sempre as motivando e dando-lhes o suporte emocional. O uso destas práticas é fundamental para prevenir intercorrências como sofrimentos físicos e/ou psicológicos para as parturientes. ${ }^{11-13}$

A assistência prestada no CPN em questão demonstra que a utilização de tecnologias leves, implica na criação de relação entre os sujeitos, além de serem imprescindíveis para o desenvolvimento de práticas respeitosas no processo de parir e na relação do binômio mãe-bebê, não sendo invasivas à fisiologia do corpo feminino, à sua mente e privacidade. Tecnologias em saúde são classificadas como: leves, leve-duras e tecnologias duras, as duas últimas, dizem respeito aos conhecimentos estruturados e saberes protocolados e equipamentos tecnológicos que atuam junto às estruturas organizacionais, as máquinas, normas e rotinas de uma instituição, respectivamente. ${ }^{14}$

Esse estabelecimento de vínculo de confiança com a Enfermeira Obstetra com caráter não invasivo tem grande significado na experiência do parto pelo modo acolhedor e atencioso em que a assistência é realizada. Isso permite que a própria parturiente conduza o seu trabalho de parto, sendo a principal protagonista deste evento fisiológico, de maneira que as pacientes conseguem perceber e relatar nas entrevistas. ${ }^{14}$

Contrapondo-se a isso, a mudança de "endereço" do parto, dos domicílios para os ambientes hospitalares, trouxe consigo a passividade das mulheres. Práticas como o uso do decúbito dorsal adotado no momento do parto, o uso de quartos coletivos, bem como a 
medicalização do corpo feminino e o uso de intervenções desnecessárias, culminaram na destituição da autonomia da mulher sobre seu corpo e, portanto, por serem realizadas com naturalidade desde meados do século XVI tornou-se algo cultural na sociedade, extraindo da mulher o direito à autonomia plena. ${ }^{15}$

Nesse ínterim, os partos em ambientes hospitalares promoveram um aumento do uso de tecnologias leve-duras e duras, com o fito de tornar o parto mais seguro. Porém, mulheres foram expostas a intervenções potencialmente iatrogênicas e não sustentadas por evidências científicas, além de não levar em consideração fatores emocionais, culturais e humanos do processo, tendo suas eficácias questionadas. ${ }^{4}$

A partir da implantação de políticas nacionais de humanização foi possível observar impactos positivos no cenário do parto e nascimento. Trata-se de estratégias que se opõem ao modelo tecnicista, devolvendo autonomia à mulher. Essas políticas buscam o resgate da naturalidade perdida ao longo da história da assistência hospitalar ao parto. ${ }^{16}$

Atualmente, o Ministério da Saúde do Brasil, por meio da Rede Cegonha, ancorado a recomendações da OMS, lançou as Diretrizes Nacionais de Assistência ao Parto. De acordo com o documento, uma série de práticas compõe o rol das consideradas "boas práticas na assistência ao parto", tais como, estímulo aos exercícios facilitadores, monitorização do bem estar fetal, oferecimento de dieta via oral, respeito à liberdade de posição, presença de acompanhante de livre escolha da mulher, entre outras., ${ }^{4,17}$ Práticas que foram amplamente incentivadas no CPN em que o estudo foi realizado.

Objetivando reduzir a mortalidade materna e infantil, a Rede Cegonha atua como uma estratégia que é organizada em quatro aspetos: pré-natal, parto e nascimento, puerpério e atenção integral à saúde da criança, além do sistema logístico que rodeia os aspectos anteriores. Para garantir o acesso, acolhimento e resolutividade, trabalha na operacionalização de políticas já existentes a partir do financiamento e atenção voltados para a estrutura física das 
maternidades e o treinamento dos profissionais de saúde para o cumprimento das boas práticas de assistência ao parto. ${ }^{18}$

Ainda no tocante a Rede Cegonha, que busca uma redução na medicalização do nascimento, os métodos não-farmacológicos de alívio da dor no trabalho de parto merecem destaque, pois além de se mostrarem majoritariamente eficazes, reduzem o uso de drogas analgésicas e ocitocina nas pacientes. Levando em conta que essa dor é resultante de mecanismos sociológicos, psicológicos e obstétricos, as intervenções devem ir para além dos medicamentos. Tais métodos incluem massagens corporais, banhos, técnicas de respiração, deambulação ativa, além de suporte físico e emocional, estratégias relatadas pelas puérperas participantes do estudo. ${ }^{19}$ Apesar da clareza nas recomendações baseadas nas evidências científicas, frequentemente há relatos da utilização de práticas consideradas prejudiciais e que devem ser eliminadas. Compõem estas categorias, técnicas com o uso do Kristeller (pressão na parte superior do útero), o uso de amniotomia, episiotomia e a ocitocina de rotina, o enema e tricotomia, além da massagem perineal. O uso rotineiro da ocitocina, exemplo relatado pelas puérperas, diminui o tempo de trabalho de parto e pode gerar a hiperestimulação do útero, provocando o aumento das dores e podendo causar taquisistolia. Quando usada de forma desnecessária é considerada uma prática danosa. ${ }^{4,17}$ Dessas práticas, apenas um relato trouxe o uso da ocitocina, demonstrando que esse método não é utilizado rotineiramente no CPN.

A partir da experiência relatada pelas mulheres acerca da assistência, percebe-se, então, que embora tenha existido uma predominância na satisfação dos serviços prestados pela enfermagem obstétrica, ainda se encontram imbuídos aos sentimentos das mulheres, questões culturais fortes provenientes de um modelo tradicional. Práticas atualmente consideradas violências obstétricas são solicitadas pelas mulheres por desconhecimento ou desinformação. Faz-se necessário dar voz a essas experiências e levar até elas a informação para a melhoria da assistência prestada. ${ }^{20}$ 
As práticas consideradas violências obstétricas, no cenário hospitalar, podem assumir várias faces, indo desde agressões verbais e humilhações à negligência e violência física, como a manobra de Kristeller, por exemplo. As formas mais comuns de violência durante o parto são: recusa de admissão em maternidade, impedimento da entrada de acompanhante, ações que interfiram no corpo da mulher causando danos ou dor, como administração de ocitocina para acelerar o trabalho de parto de forma rotineira, exames de toque demasiados e feitos por diversas pessoas, jejum forçado, episiotomia, imobilização, entre outras, ${ }^{21}$ as quais não foram identificadas neste estudo.

Ademais, é considerado violência obstétrica qualquer ação ou ato, verbal ou não, que traga à tona sentimentos negativos na parturiente, como angústia, medo, vulnerabilidade e inferioridade. Tais práticas tornaram-se comuns aos olhos das mulheres por serem feitas demasiadamente, logo, empoderar e ofertar conhecimento as mulheres é eficaz no combate a esse mal e práticas afins devem ser elaboradas e praticadas. ${ }^{21}$

Foi possível observar no estudo que algumas mulheres ainda ficam aflitas em relação ao lugar em que vão parir, esse receio é advindo de informações negativas a respeito do local onde parir. A OMS reconhece a situação em relação a notícias negativas acerca do local e do atendimento em blogs e traz o esclarecimento das gestantes como meio de diminuir esse medo. ${ }^{22}$

As estruturas hospitalares hegemônicas no Brasil são consideradas ambientes não familiares, que detém o poder de decisões importantes sob o controle do profissional. Exemplos dessas decisões são quando e como será o parto, a permissão ou não de acompanhante e o uso de práticas nem sempre consentidas pela mulher, além de terem sua privacidade e autonomia furtadas pelo modelo assistencial tecnocrático. ${ }^{23}$

Os CPNs foram criados a partir da Portaria do Ministério da Saúde nº 985/GM, em 05 de agosto de $1999 .{ }^{24}$ Eles têm objetivo de tornar o local de assistência ao parto semelhante com ambiente domiciliar, proporcionando a presença de acompanhante de livre escolha da mulher e considerando-a 
protagonista do seu momento de parir. Além disso, favorece uma melhor relação entre equipe e cliente, oportunizando tomada de decisões respeitosas durante o trabalho de parto e parto. ${ }^{13}$

Desse modo, o CPN visa oferecer ainda, intimidade e privacidade para que momento com banhos quentes, caminhadas e exercícios sejam encorajados, de forma a favorecer a evolução fisiológica do trabalho de parto. ${ }^{25}$ É importante mencionar que segundo a OMS, o enfermeiro obstetra é o profissional mais adequado para assistir a gestação e ao parto normal neste cenário. ${ }^{22}$

Contudo, apesar da satisfação com o atendimento, a maioria das mulheres entrevistadas relatou desconhecer o papel do enfermeiro obstetra (EO) naquele serviço. No entanto, o profissional possui respaldo legal nas suas funções, tendo especialização em obstetrícia esse é um profissional apto para realizar partos à luz da Lei Federal 7.498/198 - lei do exercício profissional. ${ }^{26} \mathrm{O}$ EO é capacitado para dar assistência ao parto normal sem distócia fazendo uso das práticas baseadas em evidências científicas, conforme preconiza a OMS. ${ }^{22}$ Sua atuação nos CPNs e/ou casas de parto é normatizada pela resolução do Conselho Federal de Enfermagem № 478/ 2015 que delimita suas competências em tal âmbito. ${ }^{27}$

Embora a atuação do EO seja devidamente regulamentada, tal prática ainda é pouco expressiva, aspecto este evidenciado pelos depoimentos das mulheres que participaram do estudo. Tais discursos estão ancorados ao panorama que compõe o movimento de transição do modelo de assistência ao parto. Os dados apresentados, oriundos dos discursos de usuárias, indicam que a atuação da enfermagem obstétrica é bem-vinda. Entretanto, é visível a necessidade urgente de inserção e divulgação das suas competências, possibilitando a ampliação da compreensão das mulheres acerca do seu papel, pois, de acordo com as evidências científicas, esse profissional qualifica a assistência ao atuar sobre a ótica da desmedicalização do corpo feminino e humanização do parto..$^{22,28}$ Em conformidade com o amparo legal, a OMS recomenda maior envolvimento da enfermagem obstétrica na assistência ao parto de baixo risco, considerando sua formação voltada ao cuidado e não à intervenção, sendo definido como um 
17 | Lima BCA, Almeida HKSL, Melo MCP, Morais RJL

profissional com mais disponibilidade para atender as necessidades das parturientes, posto que essa relação é construída por laços afetivos e confiança, ambos bem delimitados. O que determinou que as puérperas participantes do presente estudo descrevessem este profissional como detentora de competência técnica científica após serem assistidas, mesmo com o desconhecimento prévio da função destes. ${ }^{29}$

Assim, o profissional de enfermagem deve agir de forma a promover o resgate ao parto como fisiológico, visando à integralidade e individualidade de cada parturiente. ${ }^{29}$ Contudo, a inserção e o reconhecimento da profissão nesse cenário exige quebra de paradigmas sociais e institucionais, visto que necessita de comprometimento gestor, uma vez que haverá oposição dos setores interessados pela manutenção do atual modelo tecnocrático, pois acredita-se que a ampliação plena da autonomia da enfermagem obstétrica poderá se dar mediante um novo modelo assistencial, baseado nos saberes e competências. ${ }^{30}$

Este estudo teve algumas limitações e barreiras, que devem ser descritas. Foi possível identificar uma demanda inferior à capacidade instalada do CPN. Visto que durante período de coleta, os quartos disponíveis poucos estavam em funcionamento, dificultando o acesso de pacientes ao local. Ademais, houve uma aversão das mulheres ao gravador, mesmo depois de esclarecidas as questões de sigilo e confidencialidade do estudo, o que ocasionou a recusa de cinco puérperas em participar da pesquisa.

\section{Conclusão}

A análise dos depoimentos permitiu observar que as puérperas expressaram percepções positivas em relação a experiência do parto assistido pela enfermagem obstétrica no CPN, sendo parte delas relacionadas a uma assistência acolhedora, pautada na orientação, apoio emocional e formação de vínculo. Além disso, foram evidenciados no conteúdo das entrevistas, sentimentos significantes advindos de condutas profissionais, tais como: estímulo aos exercícios para alívio 
da dor, monitorização fetal, incentivo a dieta oral e presença de acompanhante, práticas baseadas em evidências científicas e recomendadas pela Rede Cegonha e OMS.

Foi possível constatar, que embora as impressões relacionadas à assistência prestada mostraram-se positivas, ficou evidente um desconhecimento das atribuições do Enfermeiro Obstetra, da estrutura do CPN e até mesmo do modelo obstétrico centrado em suas necessidades. Ainda no contexto da Rede Cegonha foi possível concluir que a estrutura do CPN proporcionou privacidade, conforto e tranquilidade - elementos indispensáveis para que o processo de parir transcorra sem complicações, gerando sentimentos de segurança e bem estar, e proporcionando sentimentos tais como, o acolhimento e vínculo.

Acredita-se que os resultados desta pesquisa contribuam para a prática dos profissionais de saúde, sobretudo da enfermagem obstétrica e o seu modelo assistencial, permitindo que seja compreendida a visão das pacientes sobre a sua assistência e possam, a partir disso, moldar sua prática. Além disso, o presente estudo contribui para que seja difundido o conhecimento acerca das atribuições da enfermagem obstétrica, já que tal profissão e seu papel mostraram-se desconhecidos nos resultados aqui descritos.

Ademais, este estudo serve como subsídio para o ensino e pesquisa, tendo-o como base para análise do modelo assistencial, da teoria à prática e incitando novas pesquisas, projetos de extensão e educação em saúde, expandindo o conhecimento científico para além dos muros das universidades, difundindo para a população as atribuições e a importância da enfermagem obstétrica e de instalações como o CPN.

\section{Referências}

1. Brasil G, Neves DC, Maciel DMVL, Figueredo RC. Parto no Brasil: intervenção médica ou protagonismo da mulher? Scire Salut. 2018;8(2):9-23. doi: https://doi.org/10.6008/CBPC22369600.2018.002.0002 
2. Souza FMLC, Santos WN, Santos RSC, Rodrigues OB, Santiago JCD, Silva RAR. Tecnologias apropriadas ao processo do trabalho de parto humanizado. Enferm Foco [Internet]. 2019 [acesso em 2020 fev 10];10(2):118-24. Disponível em: http://revista.cofen.gov.br/index.php/enfermagem/article/view/2180

3. Cavaler CM, Castro A, Figueiredo RC, Araújo TN. Representações sociais do parto para mulheres que foram parturientes. ID On Line Rev Psicol. 2018;12(41):977-90. doi: https://doi.org/10.14295/idonline.v12i41.1158

4. Ministério da Saúde (BR), Secretaria de Ciência, Tecnologia e Insumos Estratégicos, Departamento de Gestão e Incorporação de Tecnologias em Saúde. Diretrizes nacionais de assistência ao parto normal: versão resumida [Internet]. Brasília (DF): Ministério da Saúde; 2017 [acesso em 2020 fev 10]. Disponível em: http://bvsms.saude.gov.br/bvs/publicacoes/diretrizes_nacionais_assistencia_parto_normal.pdf

5. BRASIL. Ministério da Saúde. Portaria n. 11/GM, de 07 de janeiro de 2015. Redefine as diretrizes para implantação e habilitação de Centro de Parto Normal (CPN), no âmbito do Sistema Único de Saúde (SUS), para o atendimento à mulher e ao recém-nascido no momento do parto e do nascimento, em conformidade com o Componente Parto e Nascimento da Rede Cegonha, e dispõe sobre os respectivos incentivos financeiros de investimento, custeio e custeio mensal. Brasília, DF: Ministério da Saúde, 2015. Diário Oficial da União: seção 1, p. 30-35, 07 jan. 2015. Disponível em: https://www.jusbrasil.com.br/diarios/82851618/dou-secao-1-08-01-2015-pg-30. Acesso em: 10 fev. 2020.

6. Dias PF, Miranda TPS, Santos RP, Paula EM, Bem MMS, Mendes MA. Concept formation of ambience for labor and normal institutionalized delivery. Rev Bras Enferm. 2019;72(3):348-59. doi: https://doi.org/10.1590/0034-7167-2018-0698

7. Duarte MR, Alves VH, Rodrigues DP, Marchiori GRS, Guerra JVV, Pimentel MM. Percepção das enfermeiras obstétricas na assistência ao parto: resgate da autonomia e empoderamento da mulher. Rev Pesq Cuid Fundam. 2020;12:903-8. doi: https://doi.org/10.9789/2175-5361.rpcfo.v12.7927

8. Minayo MCS. O desafio do conhecimento: pesquisa qualitativa em saúde. 13ª ed. São Paulo: Hucitec; 2013.

9. Carvalho SS, Oliveira BRD, Nascimento CSOD, Gois CTDS, Pinto IO. Perception of a nursing team in the implantation of a reception with risk classification sector for pregnant women. Rev Bras Saúde Mater Infant. 2018;18(2):301-7. doi: http://dx.doi.org/10.1590/1806-93042018000200004

10. Behruzi R, Hatem M, Goulet L, Fraser WD. Perception of humanization of birth in a highly specialized hospital: let's think differently. Health Care Women Int. 2014;35(2):127-48. doi: https://doi.org/10.1080/07399332.2013.857321

11. Marins RB, Cecagno S, Gonçalves KD, Braga LR, Ribeiro JP, Soares MC. Care techniques for pain relief in birthing. Rev Pesq Cuid Fundam. 2020;12:265-70. doi: https://doi.org/10.9789/21755361.rpcfo.v12.8502 
12. Silva IA, Silva PSF, Andrade ÉWOF, Morais FF, Silva RSS, Oliveira LS. Percepção das puérperas acerca da assistência de enfermagem no parto humanizado. Rev Uningá [Internet]. 2018 [acesso em 2020 fev 10];53(2):37-43. Disponível em: http://revista.uninga.br/index.php/uninga/article/view/1440

13. Ribeiro JF, Lima MR, Cunha SV, Luz VLE, Coêlho DM, Feitosa VC, et al. Percepção das puérperas sobre a assistência à saúde em um centro de parto normal. Rev Enferm UFSM. 2015;5(3): 521-30. doi: https://doi.org/10.5902/2179769214471

14. Duarte MR, Alves VH, Rodrigues DP, Souza KV, Pereira AV, Pimentel MM. Care technologies in obstetric nursing: contribution for the delivery and birth. Cogitare Enferm. 2019;24:e54164. doi: https://doi.org/10.5380/ce.v24i0.54164

15. Chadwick R. Ambiguous subjects: Obstetric violence, assemblage and South African birth narratives. Fem Psychol 2017;27(4):489-509. doi: https://doi.org/10.1177/0959353517692607

16. Melo LPT, Doudou HD, Rodrigues ARM, Silveira MAM, Barbosa EMG, Rodrigues DP. Practices of health professionals in delivery and birth care. Rev Rene. 2017;18(1):59-67. doi: https://doi.org/10.15253/2175-6783.2017000100009

17. Selin L, Wennerholm UB, Jonsson M, Dencker A, Wallin G, Wiberg-Itzel E, et al. High-dose versus low-dose of oxytocin for labour augmentation: a randomised controlled trial. Women Birth. 2019;32:35663. doi: https://doi.org/10.1016/j.wombi.2018.09.002

18. Guerra HS, Hirayama AB, Silva AKC, Oliveira BJS, Oliveira JFJ. Análise das ações da Rede Cegonha no cenário brasileiro. Iniciac Cient CESUMAR. 2016;18(1):73-80. doi: https://doi.org/10.17765/15181243.2016v18n1p73-80

19. Azevedo LS, Fettermann FA, Bordignon J, Rosa AB, Costa S, Donaduzzi DSS. Métodos não farmacológicos para o alívio da dor durante o trabalho de parto: vivências de enfermeiras obstétricas. Vivências. 2019;16(30):115-25. doi: https://doi.org/10.31512/vivencias.v16i30.118

20. Lyu H, Wick EC, Housman M, Freischlag JA, Makary MA. Patient satisfaction as a possible indicator of quality surgical care. JAMA Surg. 2013;148(4):362-7. doi: https://doi.org/10.1001/2013.jamasurg.270

21. Luz AA, Silva LAS, Aoyama EA, Lemos LR. As diversas faces da violência obstétrica no âmbito hospitalar. Rev Bras Interdiscip Saúde [Internet]. 2019 [acesso em 2020 maio 31];1(3):78-83. Disponível em: https://revistarebis.rebis.com.br/index.php/rebis/article/view/34

22. Organização Mundial da Saúde (OMS). Assistência ao parto normal: um guia prático [Internet]. Genebra: Organização Mundial da Saúde; 1996 [acesso em 2020 fev 10]. Disponível em: http://www.saude.mppr.mp.br/arquivos/File/kit_atencao_perinatal/manuais/assistencia_ao_parto_normal _2009.pdf

23. Medeiros RMK, Figueiredo G, Correa ÁCP, Barbieri M. Repercussions of using the birth plan in the 
parturition process. Rev Gaúcha Enferm. 2019;40:e20180233. doi: https://doi.org/10.1590/19831447.2019.20180233

24. BRASIL. Ministério da Saúde. Portaria no 985/GM, de 05 de agosto de 1999. Cria o Centro de Parto Normal CPN, no âmbito do Sistema Único de Saúde. Diário Oficial da União, Brasília, DF: Ministério da Saúde, 1999. Diário Oficial da União: seção 1, p. 51-52, 04 ago. 1999. Disponível em: https://www.jusbrasil.com.br/diarios/1343883/pg-51-secao-1-diario-oficial-da-uniao-dou-de-06-081999?ref=previous_button. Acesso em: 20 fev. 2020.

25. Dias PF, Miranda TPS, Santos RP, Paula EM, Bem MMS, Mendes MA. Formação do conceito ambiência para trabalho de parto e parto normal institucionalizado. Rev Bras Enferm. 2019;72: 348-59. doi: https://doi.org/10.1590/0034-7167-2018-0698

26. Almeida BS, Morais AC, Morais AC, Rodrigues US, Campos VS, Santos WAA. Autonomia percebida pelo enfermeiro obstetra na sala de parto. Rev Eletrônica Acervo Saúde. 2020;12(1):1-7. doi: https://doi.org/10.25248/reas.e2073.2020

27. CONSELHO FEDERAL DE ENFERMAGEM. Resolução no 478, de 14 de abril de 2015. Normatiza a atuação e a responsabilidade do Enfermeiro e Obstetriz nos Centros de Parto Normal e dá outras providências. Brasília (DF): COFEN, 2015. Disponível em: http://www.cofen.gov.br/resolucao-cofen-no04782015_30969.html. Acesso em: 28 maio 2020.

28. Santos LRO, Ferreira HC, Carvalho TB. Instrumentalization of obstetric nursing residents about preparing women for childbirth: an integrative review. Res Soc Dev. 2020;9(4):e66942857. doi: https://doi.org/10.33448/rsd-v9i4.2857

29. Rabelo LR, Oliveira DL. Obstetrical nurses perceptions of their competence in assisting hospital delivery. Rev Esc Enferm USP. 2010;1(44):213-20. doi: https://doi.org/10.1590/S0080-62342010000100030

30. Melo CMM, Florentino TC, Mascarenhas NB, Macedo KS, Silva MC, Mascarenhas SN. Professional autonomy of the nurse: some reflections. Esc Anna Nery Rev Enferm. 2016;20(4):e20160085. doi: https://doi.org/10.5935/1414-8145.20160085

Editora Científica Chefe: Cristiane Cardoso de Paula

Editora Científica: Tânia Solange Bosi de Souza Magnago

Fomento / Agradecimento: Universidade Federal do Vale do São Francisco (UNIVASF)

\section{Autor correspondente}

Ramon José Leal de Morais

E-mail: ramonmorais_dm@hotmail.com 
Endereço: Rua Lucyanno Patriota, 200, bloco L, apt 203, vila moco, Petrolina - PE

CEP: 56.306-405

\section{Contribuições de Autoria}

\section{1 - Bruna Cristina de Araujo Lima}

Concepção e desenho do estudo/pesquisa; análise e/ou interpretação dos dados; revisão final com participação crítica e intelectual no manuscrito.

\section{2 - Hevelyn Kelly Samara Leite de Almeida}

Revisão final com participação crítica e intelectual no manuscrito; análise e/ou interpretação dos dados.

\section{3 - Mônica Cecília Pimentel de Melo}

Revisão final com participação crítica e intelectual no manuscrito, análise e/ou interpretação dos dados.

\section{4 - Ramon José Leal de Morais}

Concepção e desenho do estudo/pesquisa; análise e/ou interpretação dos dados; revisão final com participação crítica e intelectual no manuscrito.

\section{Como citar este artigo}

Lima BCA, Almeida HKSL, Melo MCP, Morais RJL. Nascimentos da cegonha: experiência de puérperas assistidas pela enfermagem obstétrica em Centro de Parto Normal. Rev. Enferm. UFSM. 2021 [Acesso em: Anos Mês Dia]; vol.11 e27:1-22. DOI: https://doi.org/10.5902/2179769246921 